\section{Callisthenic Productivity. A Challenge for the Traditional Economic Productivity Indicators}

\section{Iris MIHAI ${ }^{1}$}

${ }^{1} \mathrm{PhD}$, West University of Timisoara, Romania iris.mihai@e-uvt.ro
Abstract: Measuring economic productivity is a challenging task, mainly because we cannot isolate completely the effects produced by individual inputs, nor can we measure precisely how their interaction affects the overall result. In this paper we will test a new way of measuring economic productivity at country level that takes into account also the social dimension and the sustainability over time - we call it callisthenic productivity. The indicator has been built by measuring economic productivity as a sum of labor and capital productivity, which afterwards we adjust by using the Gini coefficient, the human development index, the biocapacity and the ecologic footprint of consumption. The end result is not necessarily a better way to represent a country's productivity, but rather a better way to compare the ability of countries to generate effective, reliable and sustainable economic productivity.

Keywords: productivity, measurement, indicator, callisthenic productivity.

How to cite: Mihai, I. (2021). Callisthenic Productivity. A Challenge for the Traditional Economic Productivity Indicators. Logos Universality Mentality Education Novelty: Economics and Administrative Sciences, 6(1), 01-19. https://doi.org/10.18662/lumeneas/6.1/25 


\section{Literature review}

Productivity is a measurement of quality and quality is a subjective attribute. We can measure productivity and compare the results of different groups, companies, countries, but the achieved results will be relevant only in the context of the analysis. The economic productivity of a country measures that country's capacity to use the resources it has at its disposal in an effective way, so that it gets the most out of them, identifying the optimal combinations. The capacity of the country and its operational limitations represent the framework within which the country creates and implements its development strategy.

The capacity of the country consists of its physical, financial, human and intellectual assets. The strengths and weaknesses of the government and the whole institutional structure influence the development goals, their quality and sustainability over time, and their competitiveness in relation to the development goals of the rest of the world.

In order to achieve the best performance at all levels a country needs to take into account elements like:

- Which are the factors that can influence the success of alternative options?

- Which are the key performance indicators that justify choice between alternative options?

- Which are the strengths and weaknesses/benefits and costs of each alternative?

- Which choice brings the biggest benefits for the population?

- Which is the development model that proves most suitable for the local particularities?

Capturing the outturn of the productive factors (Samuelson \& Nordhaus, 1995) is one of the main goals of measuring productivity, however, productivity can be influenced by a variety of factors like the labor force, the importance of the social milieu and the relationship among people (Bandiera et al., 2009), the knowledge and skills of the leaders (Bloom \& Van Reenen, 2007), the form of organization (Garicano \& Heaton, 2007), the motivation or de-motivation from the differentiated pay (Lazear, 2000) or the more striking differences between the quality of human capital from two companies or two countries.

There are several methods and techniques for measuring productivity like the Bennet-Bowley productivity indicator (Bennet, 1920), 
Fisher productivity index (Fisher, 1922), Törnqvist productivity index (Törnqvist, 1936), Malmquist productivity index (Caves et al., 1982), HicksMoorsteen productivity index (Diewert, 1992) and Luenberger productivity indicator (Chambers, 1996). Further discussions on the theory of productivity or the indexes used to capture it can be found in Ackerberg et al. (2007), Blundell and Bond (2000), Griliches and Mairesse (1998), Levinsohn and Petrin (2003), Olley and Pakes (1996), etc. More complex models that deal with heterogeneous-productivity producers have been developed by Asplund and Nocke (2006), Ericson and Pakes (1995), Foster et al. (2008), Hopenhayn (1992), Jovanovic (1982), Melitz (2003), etc.

For the purposes of this paper we approach productivity from a more comprehensive perspective, encompassing distributional implications, human development and the capacity of the country to provide for its citizens and also to absorb the results and/of effects of all the production processes. Similar studies have been conducted by Aoyama et al. (2010), Badinger (2008), Becchetti et al. (2013), Chatzimichael and Tzouvelekas (2013), Fulginiti and Perrin (2005), Ilmakkunas and Piekkola (2014), Restuccia and Rogerson (2013), Rios-Rull and Santaeulalia-Llopis (2010), etc.

\section{Methodology}

The methodology used for the empirical analysis of this paper has been developed by the author in a previous unpublished study. We consider the effects of the social and ecological dimension to be multiplicative and tot additive because they support and influence each other, creating a stronger aftermath than each of them would have if isolated. The model is captured by the following equation:

$$
\begin{aligned}
& \varepsilon=\mathrm{W} * \frac{1}{\mathrm{GINI}} * \mathrm{HDI} * \frac{\beta}{\mathrm{EFC}} \\
& \varepsilon-\text { National Economic Calisthenic Productivity } \\
& \text { W - Productivity } \\
& \text { GINI - The GINI coefficient } \\
& \text { HDI - Human Development Index } \\
& \beta \text { - Biocapacity } \\
& \text { EFC - Ecological Footprint of Consumption }
\end{aligned}
$$

The equation of national economic callisthenic productivity is obtained as a sum of labor and capital productivity (as ratio of GNI to EMPC plus ration of GNI to GCF) adjusted by the Gini coefficient, the 
Human Development Index and the ratio of a country's biocapacity to its ecological footprint of consumption' (Mihai, 2019).

\section{Data pool}

The empirical analysis has been carried over 71 countries from all over the globe. Their selection has been made based on data availability. The two main data sources have been The World Bank and The Global Footprint Network; from the first data base we have gathered the data for the first part of the equation: Gross National Income, Compensation of Employees, Gross Capital Formation, Gini Coefficient, Human Development Index, while for the last term, we have used the data provided by the GFN. The most recent available data has been for 2014 and the results are presented in the following section.

\section{Empirical analysis}

We have started the research by calculating and representing the levels of national economic productivity as a sum of labor and capital productivity. There is no other reason for adding the two than the fact that we wanted to take them into account both together and separately. Together as they represent a cumulated output of the economic processes carried in the analyzed countries and separate because they tell two different stories. We can observe that the national economic productivity is mostly determined by the labor productivity rather than the capital productivity. Part of the explanation is the fact that capital productivity can be improved up to a point, which is in most cases determined by the available raw materials and technology, while labor productivity tends to be able to be improved permanently, mostly due to the capacity of humans to learn, to improve, to create, to innovate and, of course, to incorporate technology and know-how in their productive processes.

The chart below captures the position of the 71 selected countries in terms of their national economic productivity in 2014: 


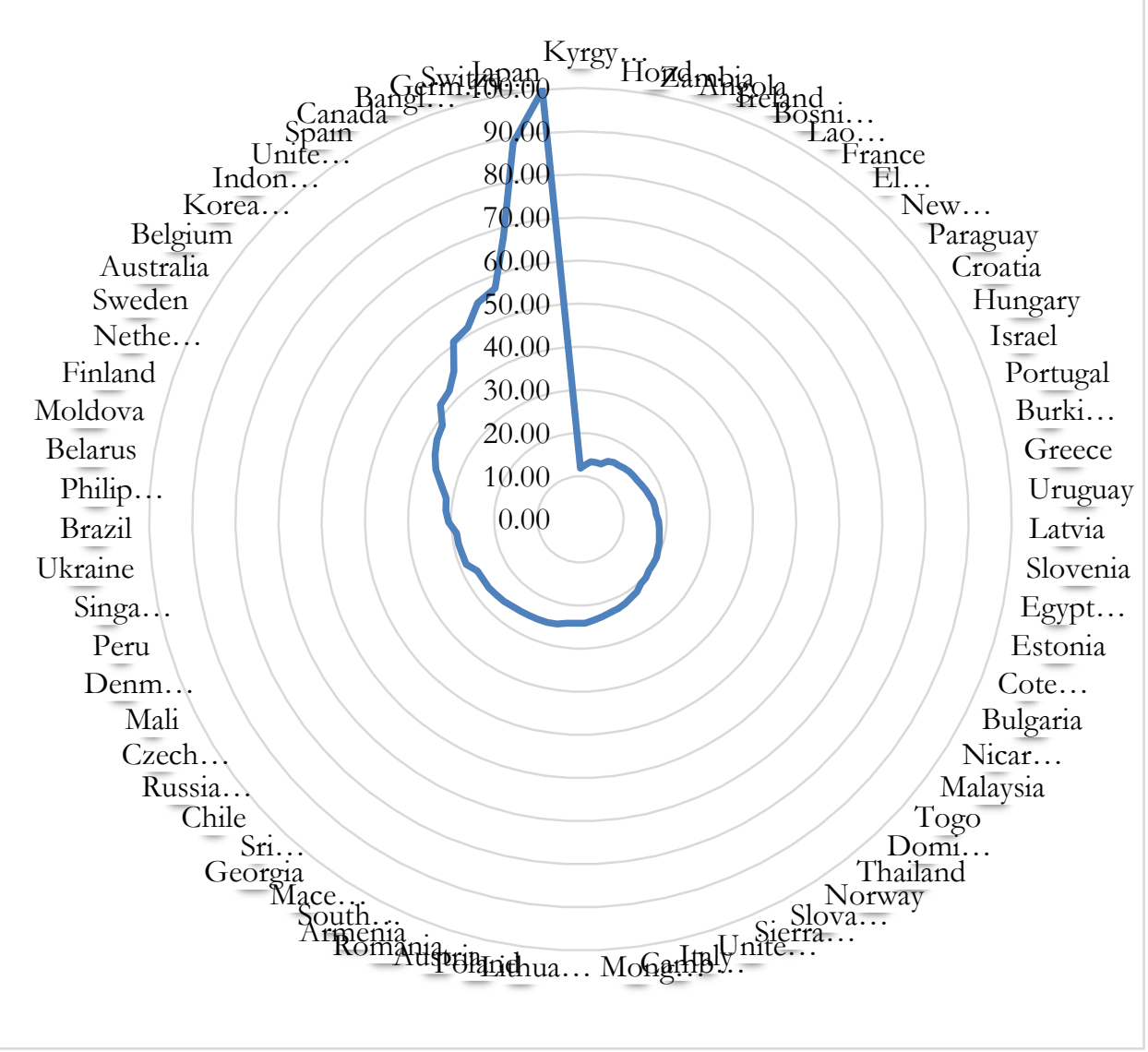

Figure 1. The level of national economic productivity in 2014 (Author's own conception)

Approximately $70 \%$ of the analyzed countries, more or less 50 of the selected ones, have productivity levels between 10-30, while the other $30 \%$ exceed it, registering productivity levels of up to 100 . In order to have a better understanding of the way productivity shifts when we introduce the social dimension and sustainability coefficients, we have split the 71 countries into three groups:

A. Low productivity (0-20)

B. Medium productivity (20-40)

C. High productivity (40-100) 
We note that ranges are not equal in size, sampling being performed by rank rather than by average. The first group includes: Kyrgyz Republic, Honduras, Zambia, Angola, Ireland, Bosnia and Herzegovina, Lao PDR, France, El Salvador, New Zealand, Paraguay, Croatia, Hungary, Israel, Portugal, Burkina Faso, Greece, Uruguay, Latvia, Slovenia, Egypt, Arab Rep., Estonia, Cote d'Ivoire, Bulgaria, Nicaragua and Malaysia.

The second group comprises: Togo, Dominican Republic, Thailand, Norway, Slovak Republic, Sierra Leone, United Kingdom, Italy, Cambodia, Mongolia, Lithuania, Poland, Austria, Romania, Armenia, South Africa, Macedonia, FYR, Georgia, Sri Lanka, Chile, Russian Federation, Czech Republic, Mali, Denmark, Peru, Singapore, Ukraine, Brazil, Philippines, Belarus, Moldova, Finland, Netherlands, Sweden and Australia.

The third group includes: Belgium, Korea, Rep., Indonesia, United States, Spain, Canada, Bangladesh, Germany, Switzerland and Japan.

Countries are listed according to the level of national economic productivity, from the lowest to the highest.

We then tested whether the level of national economic productivity correlates with population size, gross national income, labor productivity, capital productivity, GINI, or human development index. The results can be found in the table below:

Table 1. Correlation coefficient values for national economic productivity with population size, gross national income, labor productivity, capital productivity,

GINI coefficient, and human development index

\begin{tabular}{|c|c|c|c|c|c|c|c|}
\hline & & WL & WC & $\begin{array}{c}\text { GNI } \\
\$ \$\end{array}$ & GINI & HDI & Population \\
\hline \multirow{3}{*}{ Wtot } & $\begin{array}{l}\text { Pearson } \\
\text { Correlation }\end{array}$ & $.999^{* *}$ & -.025 & $.117^{*}$ & -.058 & -.269 & $.465^{* *}$ \\
\hline & $\begin{array}{l}\text { Sig. (2- } \\
\text { tailed) }\end{array}$ & .000 & .823 & .285 & .597 & .013 & .000 \\
\hline & $\mathrm{N}$ & 71 & 71 & 71 & 71 & 71 & 71 \\
\hline
\end{tabular}

(Author's own conception)

We note that between the national economic productivity and capital productivity, the GINI coefficient or the gross national income, both the values of the correlation coefficient and those of the significance are too 
weak to confirm the existence of a relationship. Between productivity and the human development index there is a poor correlation, and between productivity and population, a correlation of medium intensity, the first one, negative and the second one positive. Though the correlation between the total productivity and the human development index is not a strong one, we are surprised by the fact that it is negative, meaning the larger the HDI, the lower the productivity. This can be explained in part by the fact that the countries that have a good HDI usually have better compensation of the employees, resulting in an apparent lower labor productivity. And as we have seen, the labor productivity and the total productivity have a strong correlation, we can almost consider it a determination.

In order to have a clearer picture of the process of incorporating the social dimension into quantification of economic productivity, from this point we will continue to analyze at group level.

\section{A. Group 1. Low Productivity}

We begin by graphically representing the levels of total economic productivity in the countries belonging to the first category.

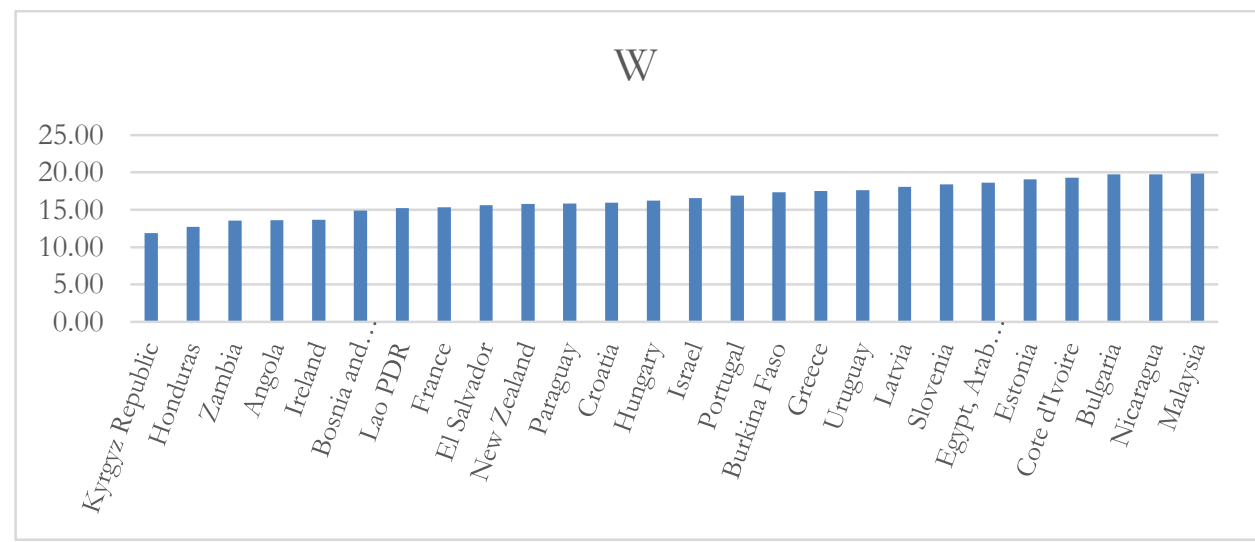

Figure 2. Level of Total Economic Productivity in Countries of the First Category Low Productivity (Author's own conception)

We find that the first category, of countries with low national economic productivity, includes eleven states in Europe, five African states, four Asian states, five in America and one in Oceania.

Next, we will adjust the national economic productivity by introducing the GINI coefficient into the equation as follows: 


$$
\mathrm{W}_{\mathrm{GINI}}=\frac{\mathrm{W}}{\mathrm{GINI}}
$$

The graph below captures the levels of national economic productivity adjusted by introducing the GINI coefficient into the equation:

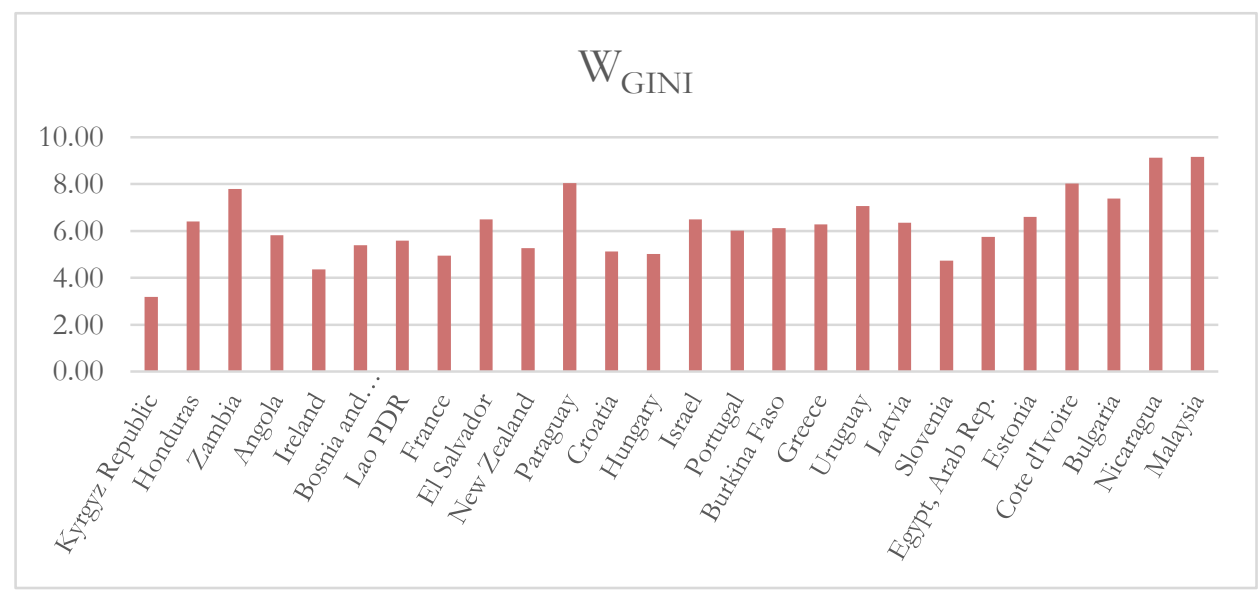

Figure 3. Level of national economic productivity adjusted by introducing the GINI coefficient for the first group of countries (Low Productivity) (Author's own conception)

We note that, following the introduction of the GINI coefficient, the levels of national economic productivity have changed considerably, changing to some extent also the hierarchy of the countries. The extremes, however, stay the same; both the lowest and the highest level of productivity remain unchanged: the Kyrgyz Republic retains the lowest productivity of 3.18, while Malaysia retains the highest level of productivity that is 9.17.

Next we will introduce the human development index and the sustainability perspective into equation, the equation taking the form:

$$
\varepsilon=(\mathrm{WL}+\mathrm{WK}) * \frac{1}{\mathrm{GINI}} * \mathrm{HDI} * \frac{\beta}{\mathrm{EFC}}
$$

The chart below captures the adjustments of national economic productivity levels following the introduction of the three dimensions of equity: income distribution, human development level and the country's biocapability ratio and the environmental footprint of its consumption.

After adjusting the national economic productivity by introducing the human development index into the equation, we notice that Ireland, New Zealand and Slovenia suffer the smallest changes due to the high level of development of these countries, their human development index having 
the following values: $0.92,0.91$ and 0.89 . The most significant differences are noted for the three African states of Liberia, Zambia and Angola, with the lowest levels of development surprised by the human development index: $0.33,0.41$ and 0.47 .

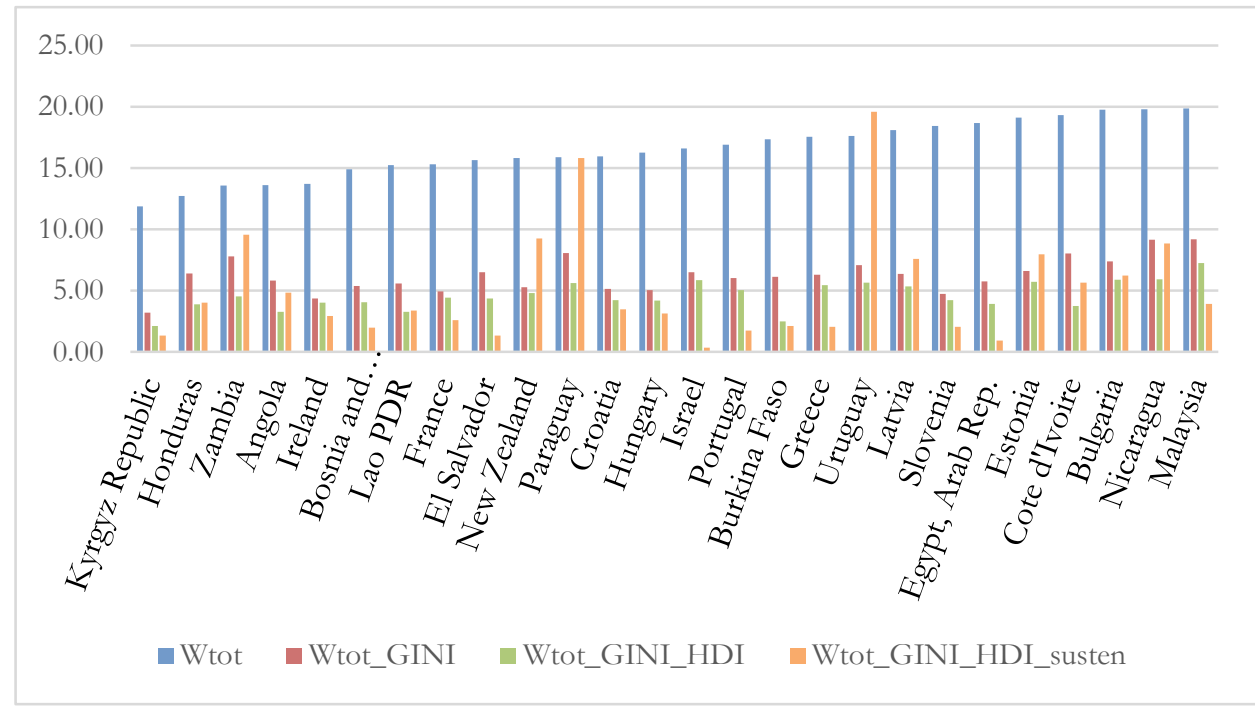

Figure 4. Levels of national economic productivity following the introduction of the three equity dimensions for the first group (Low Productivity)

(Author's own conception)

Regarding the last stage of adjusting national economic productivity levels by introducing the sustainability perspective, it significantly changes the hierarchy of states. Uruguay, Paraguay, Zambia and New Zealand take over the leadership of the group, with the most sustainable economies, with increased bio-capacities and low environmental footprints.

All the countries for which the level of economic productivity has decreased following the introduction of the third component in the equation - the ratio between biocapacity and the ecological footprint of consumption, are countries with unsustainable economies exploiting a larger biocapacity than their own and the global stock of resources. In the first group, 12 countries have sustainable economies.

Within the group, there is a strong relationship between the level of development and the ecological footprint of consumption, the value of the correlation coefficient for the two being of 0.855 (sig., 0.000). There is no relationship of dependence between the state's bio-capability and the level of 
human development, the value of the correlation coefficient being 0.109 (0.648), which leads us to the conclusion that the level of development of a state is not necessarily produced in that state, rather imported. This preliminary conclusion would explain why there are a lot of countries with increased biocapacity but with low human development levels. Regarding unadjusted national economic productivity for this group, it does not appear to be in any relationship of dependence with the other variables analyzed, but the national calist economic productivity correlates with both biocapacity and the ratio between biocapacity and the ecological footprint of consumption, without correlating with the human development index or the GINI coefficient.

\section{B. Group 2. Medium productivity}

The second group of countries, are those with average productivity, countries that have registered values for the total productivity contained within the 20-40 range. The category includes 35 countries, 18 countries from Europe, 7 from Asia, 4 from America, 5 from Africa and one country from Oceania.

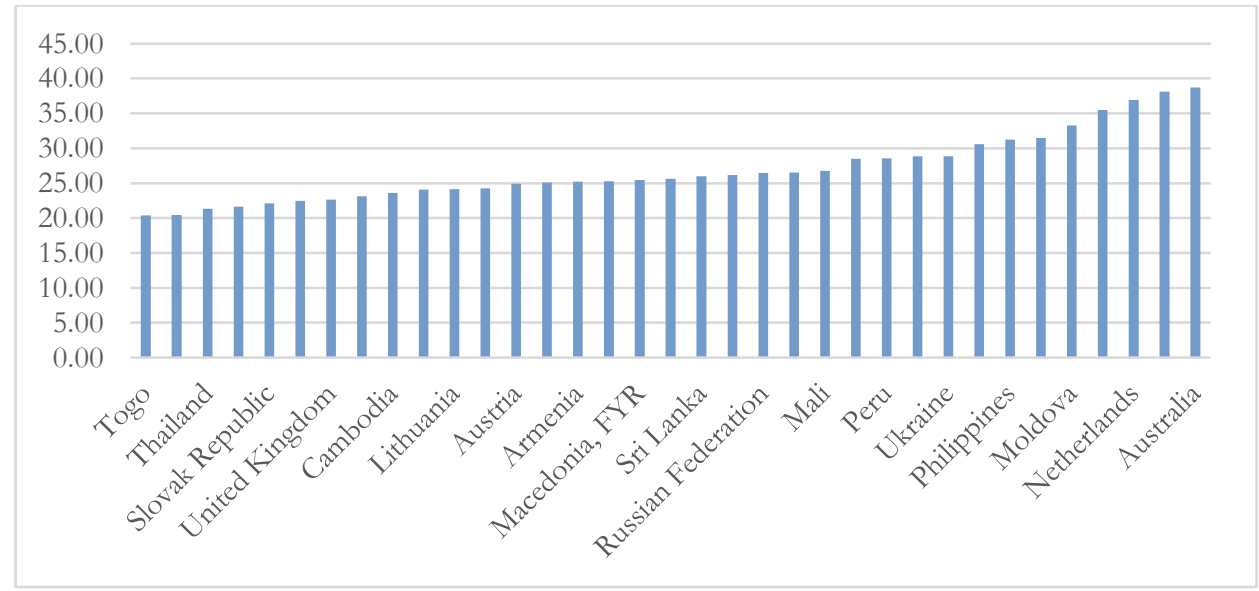

Figure 5. Total economic productivity level in the second category Average productivity

(Author's own conception)

We can observe that the top is dominated by Australia immediately followed by five European countries. The next step is to observe what 
changes when we introduce the GINI coefficient into the equation. The chart below captures the adjusted levels of national economic productivity.

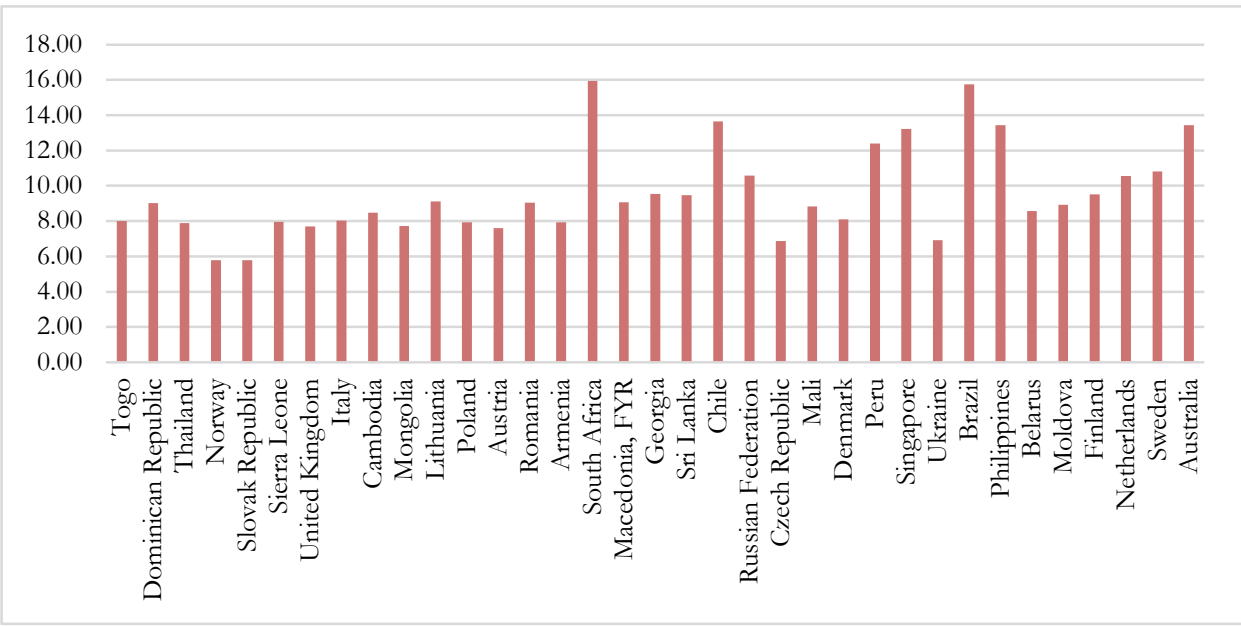

Figure 6. The level of national economic productivity adjusted by the introduction of the GINI coefficient in the second group (Average Productivity)

(Author's own conception)

We note that, following the introduction of the GINI coefficient, the levels of national economic productivity have changed considerably, changing also the hierarchy of the countries. If in the first graph the most productive state on the list was Australia, we see in this graph that the most productive state is South Africa, followed by Brazil and Chile.

Next, we will introduce the human development index and the sustainability perspective into the equation. The chart below captures the adjustments of national economic productivity levels following the introduction of the three dimensions of equity: income distribution, human development level and the country's bio-capability ratio and the environmental footprint of its consumption.

After adjusting the national economic productivity by introducing the human development index into the equation, we note that Norway, Australia, Singapore and Denmark suffer the smallest changes due to their high level of development, their human development index being 0.95 for Norway and 0.93 for the other three countries. The most significant differences are noted for Mali, Sierra Leone and Togo, with the lowest levels of development surprised by the human development index: $0.41,0.42$ and 0.48 . 
Callisthenic Productivity. A Challenge for the Traditional Economic Productivity... Iris MIHAI

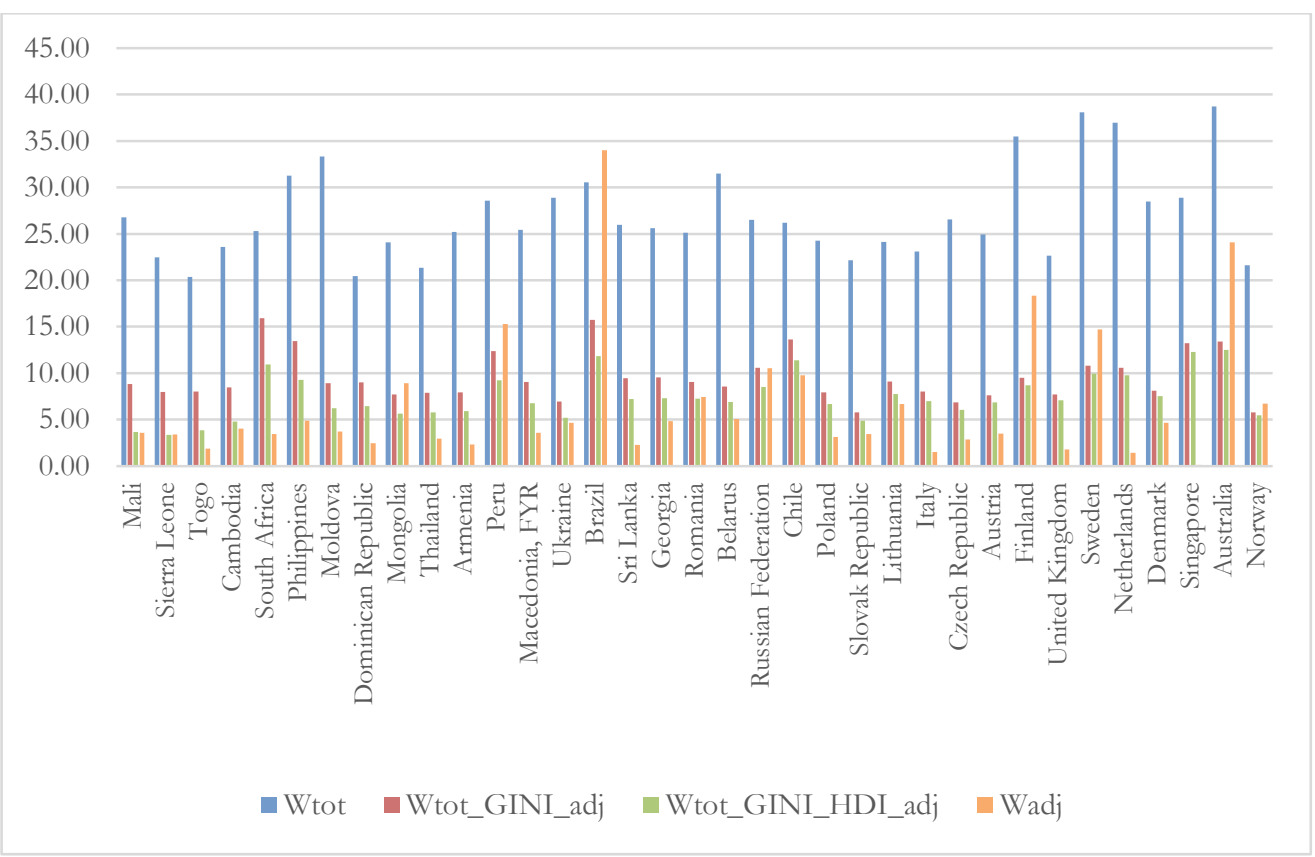

Figure 7. Levels of sustainable national economic productivity for the second group (Average Productivity)

(Author's own conception)

Regarding the last stage of adjusting national economic productivity levels by introducing the sustainability perspective, it significantly changes the hierarchy of states. Brazil and Australia take over the leadership of the group of states, with the most sustainable economies, with enhanced biocapacities and low environmental footprints.

All countries for which the level of economic productivity has decreased following the introduction of the third component in the equation - the ratio between biocapacity and the environmental footprint of consumption, are states with unsustainable economies exploiting a higher biocapacity than their own, global stock of resources. Oot of the second group, only 10 countries have sustainable economies: Finland, Australia, Brazil, Mongolia, Sweden, Peru, Norway, Russia, Romania and Sierra Leone.

At the level of the group there is an average intensity relationship between the level of development of the states and the ecological footprint of consumption, the value of the correlation coefficient for the two being of 0.693 (sig. 0.000). There is no relationship of dependence between the state's bio-capability and the level of human development, the value of the 
correlation coefficient being 0.471 (sig. 0.162), which confirms the conclusion identified for the first group, namely that the level of development of a state is not necessarily produced in that state, but rather imported. Regarding the unadjusted national economic productivity, this group does not seem to be in any relationship of dependence with the other variables analyzed, but the national economic productivity is also correlated for both the biocapacity and the ratio between biocapacity and the ecological footprint of consumption, without correlation with the human development index or the GINI coefficient.

\section{Group 3. High Productivity}

As we did for the previous groups, we will begin by representing the levels of total economic productivity in the selected countries. The last group of countries is also the smallest, including only 10 countries, four from Europe, four Asian and two North American states.

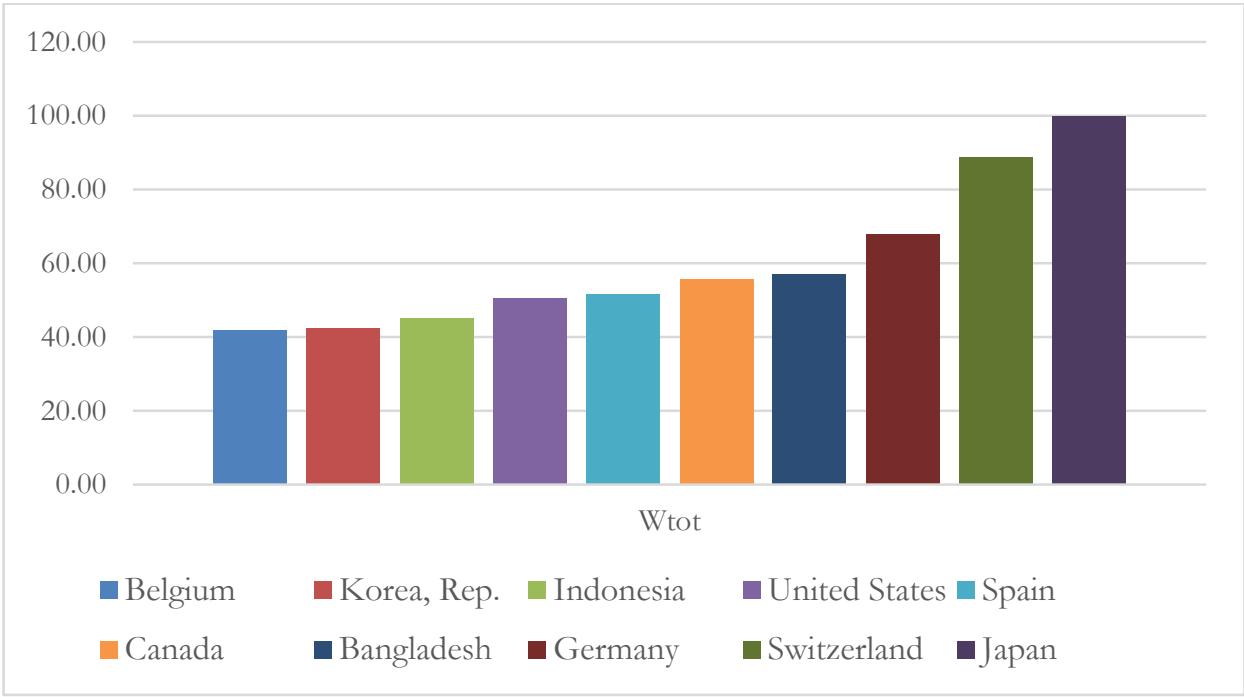

Figure 8. Total economic productivity level in the High Productivity countries (Author's own conception)

Next, we will adjust national economic productivity by introducing the GINI coefficient into the equation. The chart below captures the levels of national economic productivity adjusted accordingly. 
Callisthenic Productivity. A Challenge for the Traditional Economic Productivity... Iris MIHAI

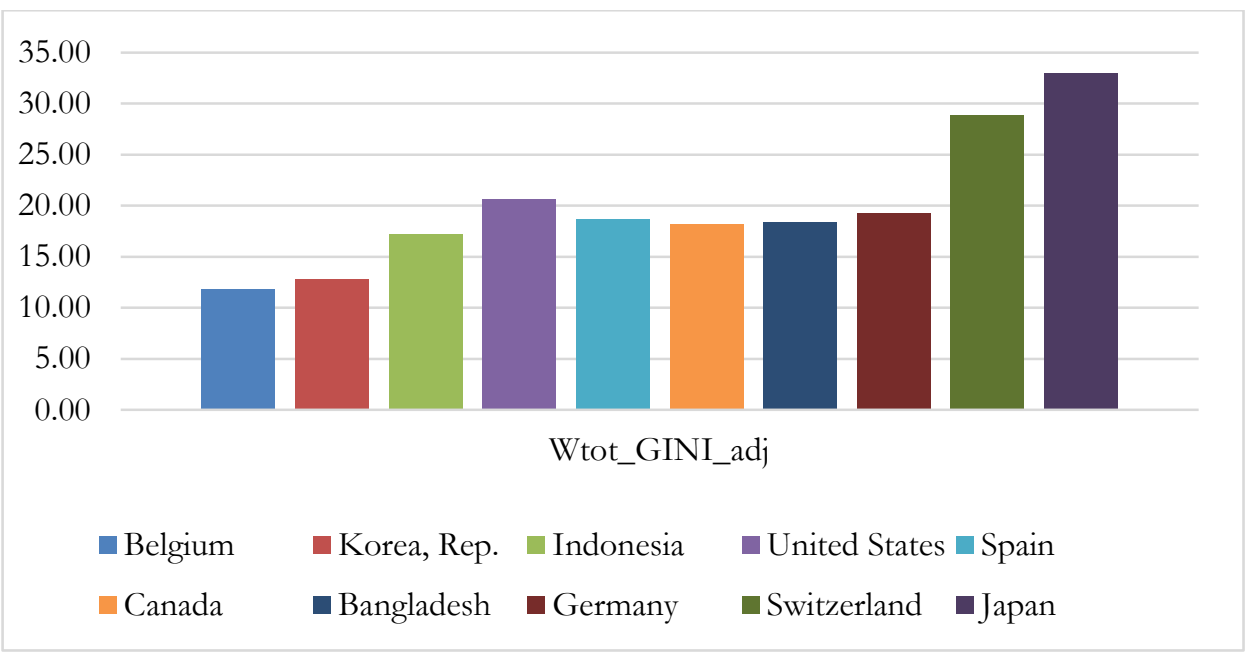

Figure 9. The level of national economic productivity adjusted by the GINI coefficient High Productivity countries

(Author's own conception)

We note that, following the introduction of the GINI coefficient, the levels of national economic productivity haven't changed considerably. This is due to the fact that the countries in the group have similar GINI coefficients and Both in the previous chart and in it, the most productive state on the list is Pakistan, followed by Japan and Switzerland. Due to the very high total economic productivity of the three states, compared to the other countries in the group, they are able to dominate the graph that captures the national economic productivity adjusted for GINI, although they do not have the best GINI coefficients. For this group, the lowest level of income distribution is in Belgium, Ethiopia and Bangladesh, 0.31 for Belgium and Ethiopia and 0.32 for Bangladesh.

Next, we will introduce the human development index and the sustainability perspective into the equation. The chart below captures the adjustments of national economic productivity levels following the introduction of the three dimensions of equity: income distribution, human development level and the country's bio-capability ratio and the environmental footprint of its consumption.

Following the adjustment of national economic productivity by introducing the human development index into the equation, we notice that Australia and the United States suffer the smallest changes due to their high level of development, with their human development index at 0.93 . The 
most significant differences are noted for the three African states Ethiopia, Uganda and Nigeria, with the lowest levels of development surprised by the human development index: 0.35, 0.43 and 0.45 .

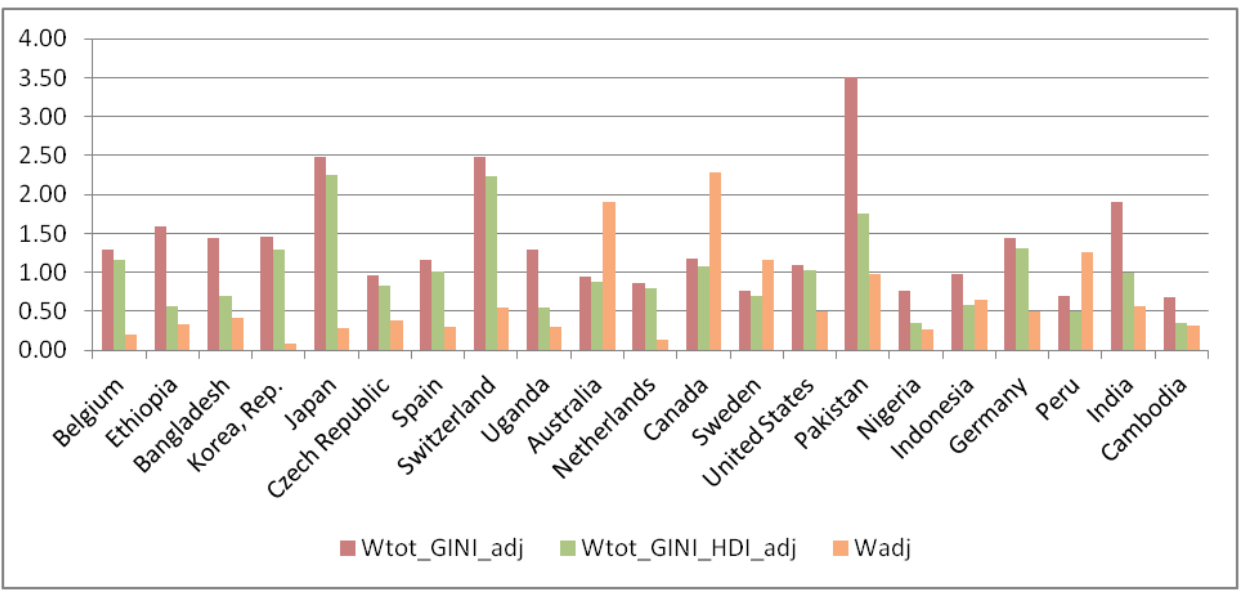

Figure 10. The level of national economic productivity following the introduction of the three equity dimensions for the last category (High Productivity)

(Author's own conception)

Regarding the last stage of adjusting national economic productivity levels by introducing the sustainability perspective, it significantly changes the hierarchy of states. Canada, Australia and Peru take over the leadership of the group of states, with the most sustainable economies, with increased bio-capacities and low environmental footprints.

All countries for which the level of economic productivity has decreased following the introduction of the third component in the equation, i.e. the ratio between biocapacity and the environmental footprint of consumption, are states with unsustainable economies exploiting a higher biocapacity than their own, global stock of resources. From the last group, only 5 states have sustainable economies, namely the three already mentioned, New Zealand, Paraguay and Angola, plus Sweden and Indonesia.

At the level of the group there is a strong relationship of dependence between the state development level and the ecological footprint of the consumption, the value of the correlation coefficient for the two being of 0.907 (sig. 0.000). Between state bio-capability and the level of human development, there is a positive, medium-intensity, but weakly related relationship of dependence, the value of the correlation coefficient being 0.434 (0.050), which also confirms the conclusion that the level of 
development of a state is not necessarily produced in that state, but rather imported. Concerning unadjusted national economic productivity, this group does not seem to be in any relationship of dependence with the other variables analyzed, but adjusted national economic productivity correlates with both the biocapacity and the ratio between biocapacity and the ecological footprint of consumption, without correlation with the human development index or the GINI coefficient.

\section{Conclusions}

The reasoning behind this research can be explained by the state of dissatisfaction generated by the misrepresentation of economic productivity levels across countries. Measuring a result without adding meaning to its implications is pointless. If we want to transform the society from within, we need to shift from profit to purpose, prom having to doing, from hierarchy to networks, from control to empowerment, from privacy to transparency (Sachs \& Kundu, 2015) and from productivity to callisthenic productivity.

We have analyzed the way economic productivity measurement is affected by encompassing the social dimension and sustainability in the equation and have understood that there is a completely different perspective, much closer to the actual state in which countries lie. Yes, the 10 most productive countries in the world seem to be leading the race, but will they be able to continue to do so without considering their limitations? Either imposed by the resources they have at their disposal or by their incapacity to reduce the gap between the rich and the poor.

Carrying the analysis has drawn a picture with very productive countries and countries lagging behind, countries rich in biocapacity and countries that rely on the global stock of resources for their well-being. Measuring the callisthenic productivity has revealed a new picture of the productivity than the one revealed by the economic productivity. Callisthenic productivity managed to highlight the effects that the economic activity produces upon the environment and upon the population. Sometimes these effects are positive and those countries become models to follow, whereas other times the effects are negative and we can learn by contrast. The main idea is that we all bear a responsibility in providing a better understanding of the world we live in so we can make a better living for ourselves and for the generations to come. 


\section{Acknowledgement}

The publication of this paper was made possible by the financial support received by the author within a post-doctoral fellowship awarded by the West University of Timisoara, Romania, The Faculty of Political Sciences, Philosophy and Communication Sciences.

\section{References}

Ackerberg, D. C., Benkard, L., Berry, S., \& Pakes, A. (2007). Econometric Tools for Analyzing Market Outcomes. In J. J. Heckman \& E. E. Leamer (Eds.), Handbook of Econometrics, Volume $6 A$ (pp. 4171-4276). Elsevier. https://web.stanford.edu/ lanierb/research/tools8l-6-8.pdf

Aoyama, H., Yoshikawa, H., Iyetomi, H., \& Fujiwara, Y. (2010). Productivity dispersion: fact, theory and implications. Journal of economic interaction and coordination, 5, 27-54. http://dx.doi.org/10.1007/s11403-010-0063-9

Asplund, M., \& Nocke, V. (2006). Firm Turnover in Imperfectly Competitive Markets. Review of Economic Studies, 73(2), 295-327. https://doi.org/10.1111/j.1467-937X.2006.00377.x

Badinger, H. (2008). Trade policy and productivity. European Economic Review, 52, 867-891. http://dx.doi.org/10.1016/i.euroecorev.2007.08.001

Bandiera, O., Barankay, I., \& Rasul, I. (2009). Social Connections and Incentives in the Workplace: Evidence from Personnel Data. Econometrica, 77(4), 10471094. http://dx.doi.org/10.3982/ECTA6496

Becchetti, L., Castriota, S., \& Tortia, E. C. (2013). Productivity, wages and intrinsic motivations. Small business economics, 41, 379-399. https://doi.org/10.1007/s11187-012-9431-2

Bennet, T. L. (1920). The Theory of Measurement of Changes in Cost of Living. Journal of the Royal Statistical Society, 83(3), 455-462. https://doi.org/10.2307/2340960

Bloom, N., \& Reenen, J. V. (2007). Measuring and Explaining Management Practices across Firms and Countries. Quarterly Journal of Economics, 122(4), 1351-1408. https://doi.org/10.1162/qjec.2007.122.4.1351

Blundell, R., \& Bond, S. R. (2000). GMM Estimation with Persistent Panel Data: An Application to Production Functions. Econometric Reviews, 19(3), 321-40. https://doi.org/10.1080/07474930008800475

Caves, D. W., Christensen, L. R., \& Diewert, W. E. (1982). Multilateral Comparisons of Output, Input and Productivity Using Superlative Index Numbers. Economic Journal, 92(365), 73-86. https://doi.org/10.2307/2232257 
Callisthenic Productivity. A Challenge for the Traditional Economic Productivity... Iris MIHAI

Chambers, R. (1996). A New Look at Exact Input, Output, Productivity and Technical Change Measurement. Working Papers 197840, Department of Agricultural and Resource Economics, University of Maryland, College Park. http://dx.doi.org/10.22004/ag.econ.197840

Chatzimichael, K., \& Tzouvelekas, V. (2013). Human capital contributions to explain productivity differences. Journal of Productivity Analysis, 41(3), 399417. http://dx.doi.org/10.1007/s11123-013-0355-x

Diewert, W. E. (1992). Fisher ideal output, input and productivity indexes revisited. Journal of Productivity Analysis, 3(3), 211-248. http://dx.doi.org/10.1007/BF00158354

Ericson, R., \& Pakes, A.(1995). Markov-Perfect Industry Dynamics:A Framework for Empirical Work. Review of Economic Studies, 62(1), 53-82. https://doi.org/10.2307/2297841

Fisher, I. (1922). The Making of Index Numbers. Houghton-Mifflin.

Foster, L., Haltiwanger, J., \& Syverson, C. (2008). Reallocation, Firm Turnover, and Efficiency: Selection on Productivity or Profitability?. American Economic Review, 98(1), 394-425. http://doi.org/10.1257/aer.98.1.394

Fulginiti, L. E., \& Perrin, R. K. (2005). Productivity and welfare. Journal of productivity analysis, 24, 133-155. https://doi.org/10.1007/s11123-005-4701-5

Garicano, L., \& Heaton, P. (2007). Information Technology, Organization, and Productivity in the Public Sector: Evidence from Police Departments. Journal of Labor Economics, 28(1), 167-201. http://dx.doi.org/10.1086/649844

Griliches, Z., \& Mairesse, J. (1998). Production Functions: The Search for Identification. NBER Working Paper Series, Working Paper no. 5067. https://www.nber.org/system/files/working_papers/w5067/w5067.pdf

Hopenhayn, H. A. (1992). Entry, Exit, and Firm Dynamics in Long Run Equilibrium. Econometrica, 60(5), 1127-1150. https://doi.org/00129682(199209)60:5\%3C1127:EEAFDI\%3E2.0.CO;2-B

Ilmakkunas, P., \& Piekkola, H. (2014). Intangible investment in people and productivity. Journaal of productivity analysis, 41, 443-456. https://doi.org/10.1007/s11123-013-0348-9

Jovanovic, B. (1982). Selection and the Evolution of Industry. Econometrica, 50(3), 649-670. https://www.andrew.cmu.edu/course/88737/dynamic/selection.pdf

Lazear, E. P. (2000). Performance Pay and Productivity. American Economic Review, 90(5), 1346-1361. http://doi.org/10.1257/aer.90.5.1346

Levinsohn, J., \& Petrin, A. (2003). Estimating Production Functions Using Inputs to Control for Unobservables. Review of Economic Studies, 70(2), 317-341. 
https://www.theigc.org/wp-content/uploads/2016/06/READINGSLevinsohn-Petrin.pdf

Melitz, M. J. (2003). The Impact of Trade on Intraindustry Reallocations and Aggregate Industry Productivity. Econometrica, 71(6), 1695-1725. https://doi.org/10.1111/1468-0262.00467

Mihai, I. (2019). Callisthenic Productivity - A Proposal for a New Productivity Indicator. Eurasian Business Review, 9, 40822.

Olley, G. S., \& Pakes, A. (1996). The Dynamics of Productivity in the Telecommunications Equipment Industry. Econometrica, 64(6), 1263-97. https:// file.lianxh.cn/Refs/TE/Gong/Olley-Pakes-1996-OP.pdf

Restuccia, D., \& Rogerson, R. (2013). Misallocation and productivity. Review of Economic Dynamics, 16(1), 1-10. https://doi.org/10.1016/j.red.2012.11.003

Rios-Rull, J. V, \& Santaeulalia-Llopis, R. (2010). Redistributive shocks and productivity shocks. Journal of Monetary Economics, 57, 931-948. https://doi.org/10.1016/i.jmoneco.2010.10.005

Sachs, A., \& Kundu, A. (2015, November 13). The Unfinished Business of Organizational Transformation. ThoughtWorks. https://www.thoughtworks.com/insights/blog/unfinished-businessorganizational-transformation

Samuelson, P., \& Nordhaus, W. (1995). Economics (15th ed.). McGraw-Hill.

Törnqvist, L. (1936). The Bank of Finland's Consumption Price Index. Bank of Finland Monthly Bulletin, 10, 28-36.

https://helda.helsinki.fi/bof/bitstream/handle/123456789/10834/Bofbul 1936-10.pd? ?sequence $=1$ 